\title{
Silent Liver Diseases in Autopsies
}

\author{
Nidhi Sheth ${ }^{1}$, Gautam Chauhan ${ }^{2}$, Rekha Iyer ${ }^{3}$ \\ ${ }^{1}$ Resident, Department of Pathology, Government Medical College, Bhavnagar 364001 \\ ${ }^{2}$ Associate Professor, Department of Pathology, Government Medical College, Bhavnagar 364001 \\ ${ }^{3}$ Assistant Professor, Department of Pathology, Government Medical College, Bhavnagar 364001
}

\begin{abstract}
Background: Liver is a major organ in our body which is vulnerable to various insults such as metabolic, toxic, microbial, circulatory and neoplastic. There may be no prominent sign and symptoms of chronic liver diseases and therefore, they may go undiagnosed or found incidentally. Objectives: The objective of the study was to find out the prevalence of silent liver diseases. Method: 349 liver autopsies specimens were assessed and 10 cases were excluded due to autolysis. Specimens were examined grossly and microscopically and findings were recorded. Results: Causes of death were- Myocardial infarction 52, RTA 39 and Poisoning 9. According to microscopic examination, majority of cases had fatty change 32.95\% followed by congestion $18.91 \%$ and normal liver 17.48\%. Interpretation and Conclusion: In this study of 349 cases, Males were 275 and Females were 74 . Incidence of liver diseases was higher in $4^{\text {th }}$ and $5^{\text {th }}$ decades. The commonest finding was fatty change.
\end{abstract}

Keywords: Chronic liver disease, Fatty change

\section{Introduction}

Liver is a major organ in our body which is vulnerable to various insults such as metabolic, toxic, microbial, circulatory and neoplastic [1]. Sometimes, the disease is primary while in others, it is secondary to alcoholism, cardiac decompensation or extra hepatic infections. There may be no prominent sign and symptoms of chronic liver diseases and therefore, they may go undiagnosed or found incidentally. The underlying causes of such chronic liver diseases vary based on age, sex, socio-economic status, life style and endemic infections. Alcohol is one of the major cause of such silent liver diseases. Alcohol abuse mainly causes three liver diseases- fatty change, hepatitis and cirrhosis [2]. Other changes seen as silent liver diseases in histopathological findings are congestion and malignancy [3]. Short term ingestion of $80 \mathrm{gm}$ alcohol produces mild and reversible fatty liver. Daily intake of $80 \mathrm{gm}$ or more increases the risk for severe hepatic injury and daily ingestion of $160 \mathrm{gm}$ or more is associated with severe injury [4].

\section{Literature Survey}

The true incidence and prevalence of silent liver diseases are not well known. This is because liver histology is required as the gold standard for precise diagnosis and as it is a invasive procedure it is still not considered essential.

\section{Material and Methods}

Ethical consideration: Permission of institutional review board before conducting the study was taken.

Sample size: The present study was conducted on liver specimens of 349 routine autopsies received in the Department of Pathology, Autopsy section, Government Medical College, Bhavnagar, Gujarat to find out the prevalence of silent liver diseases.
Methods: All the autopsy subjects irrespective of age, sex \& cause of death were included in the study. Liver specimens were examined grossly and microscopically. The specimen were fixed in $10 \%$ formalin, weighed and dimensions measured. Grossly examined for color, consistency, nodules and congestion [5]. A minimum of two sections per liver were studied, irrespective of any gross pathology seen or not. After routine processing and paraffin embedding 4 micro meter section were taken. All the sections were stained with Haematoxylin \& Eosin stain \& mounted. All the histological sections were examined microscopically \& findings were recorded [6].

\section{Results}

During the study period from January 2013 to June 2015, total of 349 cases were assessed and 10 cases were excluded due to autolysis.

Causes of death were- Myocardial infarction 52, RTA 39 and Poisoning 9.

Gross examination on the basis of color and cut-surface was observed and recorded from all 349 specimens of liver [Table-1].

Table 1: Gross Findings

\begin{tabular}{|c|c|c|c|}
\hline External surface & Nos. & Cut surface & Nos. \\
\hline Yellow green & 115 & Nodular & 19 \\
\hline Yellow brown & 100 & Greasy & 121 \\
\hline Red brown & 17 & Nutmeg & 98 \\
\hline Normal & 117 & Normal & 111 \\
\hline Total & 349 & Total & 349 \\
\hline
\end{tabular}

According to microscopic examination, majority of cases had fatty change $32.95 \%$ [Fig-1] followed by congestion $18.91 \%$ and normal liver $17.48 \%$ [Table- 2$]$. 


\section{International Journal of Science and Research (IJSR) \\ ISSN (Online): 2319-7064}

Index Copernicus Value (2013): 6.14 $\mid$ Impact Factor (2014): 5.611

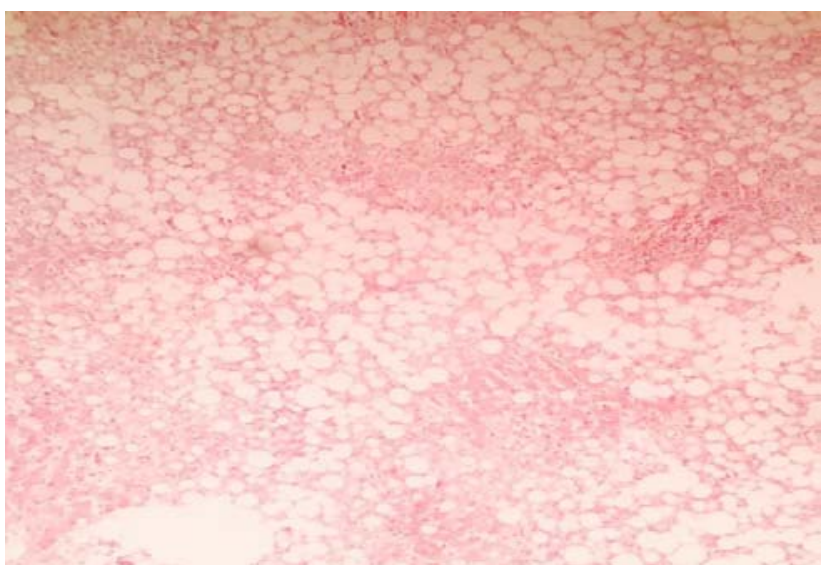

Figure 1: Fatty liver: Figure shows. (H\&E Stain)
Table 2: Percentage of various liver diseases

\section{Liver histopathology}

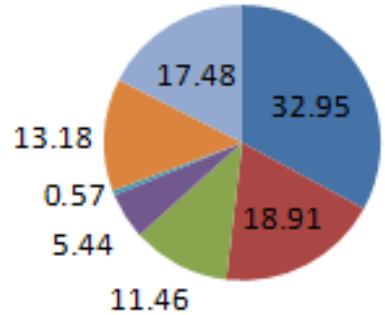

Eatty changes

- Congestion

Hepatitis

Cirrhosis

Malignancy

The age range in the study was from 4 days to 100 years. The commonest finding was fatty change which was seen more in the age of 40 years and above. In the study, out of 349 cases $78.79 \%$ were males and $21.20 \%$ were females. Male predominance is seen in the study [Table-3].

Table 3: Histopathological Findings

\begin{tabular}{|c|c|c|c|c|c|c|c|c|c|c|c|c|c|c|c|c|c|c|c|c|c|}
\hline \multirow{3}{*}{ Age } & \multicolumn{21}{|c|}{ Histopathological Findings } \\
\hline & \multicolumn{3}{|c|}{ Fatty changes } & \multicolumn{3}{|c|}{ Cirrhosis } & \multicolumn{3}{|c|}{ Congestion } & \multicolumn{3}{|c|}{ Hepatitis } & \multicolumn{3}{|c|}{ Malignancy } & \multicolumn{3}{|c|}{ Others } & \multicolumn{3}{|c|}{ Normal } \\
\hline & $M$ & $F$ & $T$ & $M$ & $F$ & $T$ & $M$ & $F$ & $T$ & $M$ & $F$ & $T$ & $M$ & $F$ & $T$ & $M$ & $F$ & $T$ & $M$ & $F$ & $T$ \\
\hline $0-30$ & 13 & 8 & 21 & 2 & 0 & 2 & 0 & 0 & 0 & 1 & 2 & 3 & 0 & 1 & 1 & 7 & 8 & 15 & 39 & 16 & 55 \\
\hline $31-40$ & 16 & 3 & 19 & 4 & 0 & 4 & 4 & 3 & 7 & 9 & 0 & 9 & 0 & 0 & 0 & 7 & 0 & 7 & 1 & 3 & 4 \\
\hline $41-50$ & 21 & 5 & 26 & 5 & 0 & 5 & 29 & 2 & 31 & 1 & 0 & 1 & 0 & 0 & 0 & 4 & 3 & 7 & 0 & 0 & 0 \\
\hline $51-60$ & 22 & 7 & 29 & 2 & 0 & 2 & 4 & 1 & 5 & 9 & 1 & 10 & 0 & 0 & 0 & 11 & 0 & 11 & 2 & 0 & 2 \\
\hline $61-70$ & 12 & 2 & 14 & 6 & 0 & 6 & 15 & 3 & 18 & 8 & 2 & 10 & 1 & 0 & 1 & 4 & 1 & 5 & 0 & 0 & 0 \\
\hline $71-80$ & 2 & 1 & 3 & 0 & 0 & 0 & 4 & 0 & 4 & 7 & 0 & 7 & 0 & 0 & 0 & 1 & 0 & 1 & 0 & 0 & 0 \\
\hline $81-90$ & 1 & 1 & 2 & 0 & 0 & 0 & 1 & 0 & 1 & 0 & 0 & 0 & 0 & 0 & 0 & 0 & 0 & 0 & 0 & 0 & 0 \\
\hline $91-100$ & 0 & 1 & 1 & 0 & 0 & 0 & 0 & 0 & 0 & 0 & 0 & 0 & 0 & 0 & 0 & 0 & 0 & 0 & 0 & 0 & 0 \\
\hline \multirow[t]{2}{*}{ Total } & 87 & 28 & 115 & 19 & 0 & 19 & 57 & 9 & 66 & 35 & 5 & 40 & 1 & 1 & 2 & 34 & 12 & 46 & 42 & 19 & 61 \\
\hline & \multicolumn{3}{|c|}{$32.95 \%$} & \multicolumn{3}{|c|}{$5.44 \%$} & \multicolumn{3}{|c|}{$18.91 \%$} & \multicolumn{3}{|c|}{$11.46 \%$} & \multicolumn{3}{|c|}{$0.57 \%$} & \multicolumn{3}{|c|}{$13.18 \%$} & \multicolumn{3}{|c|}{$17.48 \%$} \\
\hline
\end{tabular}

\section{Discussion}

In this study of 349 cases, Males were 275 and Females were 74. Incidence of liver diseases was higher in $4^{\text {th }}$ and $5^{\text {th }}$ decades. The reason for men being more prone to death by diseases in comparison to females because men are the bread earners and so they are more exposed to the outside world. There is always a silent peer pressure as drinking alcohol is such a big part of socializing among males. For them it is also about relieving stress and being carefree.

In a study conducted by Hilden et al. among 503 cases of RTA, 370 persons (74\%) had no pathological changes in the liver while Fatty liver was found in 120 persons (24\%) [7].

Bal MS et al. conducted a study in which out of 100 cases of liver specimens- fatty liver 39\%, normal $30 \%$, cirrhosis 14\%[Fig-2], congestion 9\%, hepatitis 3\%, malignancy $3 \%$ [Fig-3] and chronic abscess $2 \%$; males predominate with $83 \%$ and female $17 \%$; fatty liver was more common among 41-60 years of age [8].

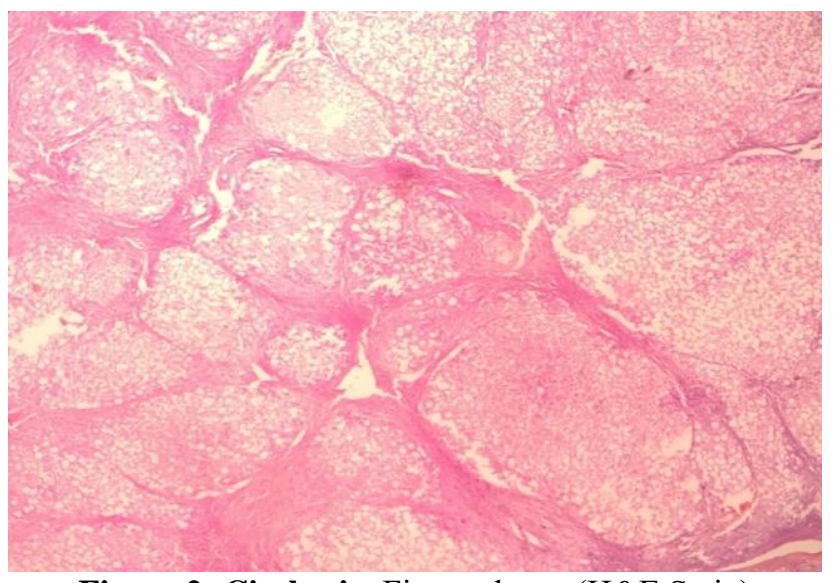

Figure 2: Cirrhosis: Figure shows (H\&E Stain) 


\section{International Journal of Science and Research (IJSR) \\ ISSN (Online): 2319-7064}

Index Copernicus Value (2013): 6.14 | Impact Factor (2014): 5.611

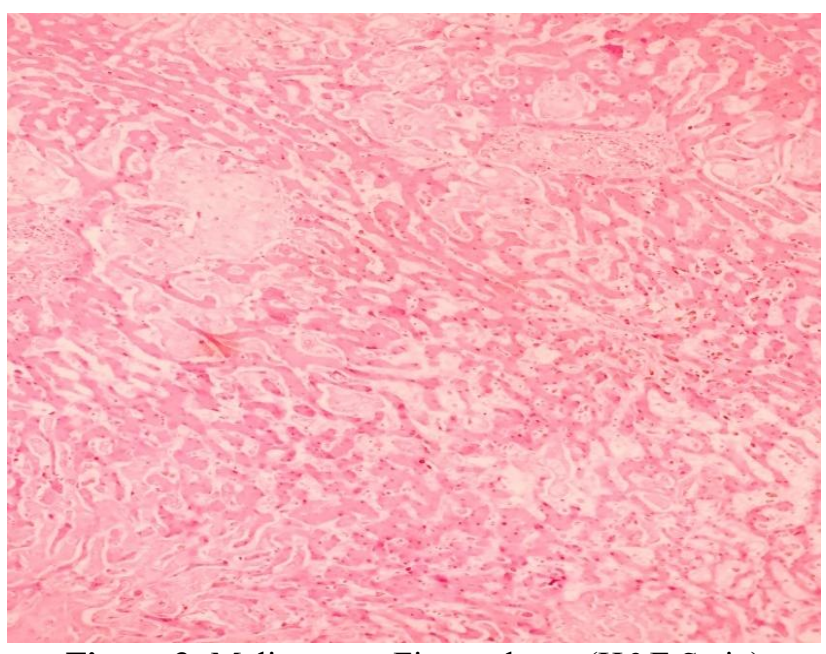

Figure 3: Malignancy: Figure shows (H\&E Stain)

\section{Conclusion}

Silent liver diseases are not uncommon. Incidence is more in males than females. The most common finding was fatty change which was more in age of 41-60 years.

\section{Future Scope}

In clinical practice, liver biopsy is only performed for highly selected patients. Therefore, the reported rates cannot reflect the true prevalence of silent liver diseases in the general population. Since they are common and may lead to serious clinical consequences, they should be considered seriously as an important threat to the health.

\section{References}

[1] Crawford JM. Liver and biliary tract. In: Robbins and Cotran $8^{\text {th }}$ eds. Pathologic basis of disease. South Asia Ed. Vol 2 New Delhi:Elsevier; 2015: P 835.

[2] Harsh mohan. The liver, Biliary tract and Exocrine pancreas. In: Harsh mohan $7^{\text {th }}$ ed. Textbook of pathology, Jaypee; 2015:P 606.

[3] Saphir O. Liver In: Paul B, Hobber, Autopsy diagnosis and techniques, $4^{\text {th }}$ ed., New York. 1958: 354-65.

[4] Crawford JM. Liver and biliary tract. In: Robbins and Cotran $8^{\text {th }}$ eds. Pathologic basis of disease. South Asia Ed. Vol 2 New Delhi:Elsevier; 2015: P 858.

[5] Gamble M. The Haematoxylins. In: Bancroft JD and Gamble M, eds. Theory and Practice of histological techniques. 6th Ed., New York: Churchill Livingstone 2008: 121-33.

[6] Rapheal SS, Hyde TA, Mellor LD eds. In: W.B. Saunders, Lynch's Medical Laboratory Technology. 4th Ed Philadelphia., 1983: 14-39.

[7] Hilden M, Christoffersen P, Juhl E, Dalgaard JB. Liver histology in a 'normal' population- examination of 503 consecutive fatal traffic casualties. Scand J Gastroenterol. 1997; 12: 593-97.

[8] Bal MS, Singh SP, Bodal VK, et al. Pathological findings in Liver autopsy. JIAFM, 2004; 26(2); 55-57.

\section{Author Profile}

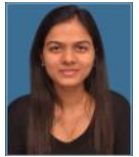

Nidhi Sheth received the M.B.B.S degree from Govt. Medical College, Bhavnagar in 2012 and currently in Final year of M.D.Pathology in the same institute.

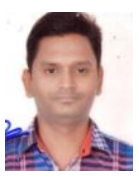

Gautam Chauhan received the M.B.B.S degree and M.D. Pathology degree from M.P.Shah Medical College, Jamnagar in 2002 and 2007, respectively. He has published many papers in various National and International journals. He now is the Associate Professor, Department of Pathology in Govt. Medical College, Bhavnagar.

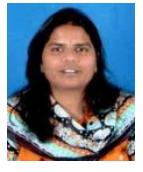

Rekha Iyer received the M.B.B.S degree and M.D. Pathology degree from Government Medical College, Bhavnagar in 2003 and 2009, respectively. She now is the Assistant Professor, Department of Pathology in Govt. Medical College, Bhavnagar. 